\title{
JOSÉ DE ALENCAR E A BRASILIDADE: UMA LEITURA HISTORIOGRÁFICA
}

\section{MARCELO DOS SANTOS CARNEIRO}

Doutorando em Letras pela Pontifícia Universidade Católica de São Paulo (PUC-SP), São Paulo, SP, Brasil.

E-mail: marceloscarneiro@yahoo.com.br

\section{Resumo}

Apresentamos uma leitura sobre José de Alencar procurando mostrar a intenção do escritor em renovar a língua portuguesa utilizada no Brasil, produto de seus anseios nacionalistas, reflexo de uma sociedade que vivia em um país de recente independência e que buscava por sua emancipação cultural. Para isso, o autor busca na língua dos índios novos vocábulos para o português brasileiro. A escolha do tema se justifica pela importância que se tem em refletir e discutir sobre as realizações culturais deste momento histórico, de formação e caracterização da cultura nacional. Sendo assim, o objetivo geral deste trabalho é mostrar que José de Alencar foi um escritor engajado com as questões políticas e culturais de seu tempo, tendo como objetivo específico analisar trechos retirados de algumas de suas obras evidenciando o "tupinismo" como as peculiaridades que as diferenciam do português europeu. A metodologia utilizada para a realização deste trabalho é de natureza bibliográfica, respaldada pelo viés historiográfico pautado na obra de Koerner (2014), que nos apresenta três princípios para um trabalho de historiografia linguística. Os aspectos da biografia do autor relevantes ao trabalho, bem como os acontecimentos da época em que 
atuou, serão vistos em Candido e Castelo (1992), Coutinho e Coutinho (2004), Magalhães Júnior (1970) e Rodrigues (2001).

\section{Palavras-chave}

José de Alencar. Língua Portuguesa. Ruptura Cultural.

\section{INTRODUÇÃO}

Inspirados pela independência do país, os brasileiros passaram a nutrir um sentimento antilusitano e um consequente nacionalismo e patriotismo que transcendeu ao campo da política chegando à cultura. Os intelectuais, principalmente no segundo império, produziam seus trabalhos em um momento de "efervescência cultural” promovida pelo então imperador D. Pedro II (1825-1891).

Defensor da educação, o imperador foi o responsável pela criação do Instituto Histórico e Geográfico Brasileiro (IHGB) e da Imperial Academia de Música e Ópera Nacional, pela fundação do Colégio Pedro II, entre outras escolas, e a Imperial Escola de Belas Artes, criada por seu pai, passou a receber maior apoio, além de providenciar bolsas de estudo para que os artistas e intelectuais pudessem estudar na Europa. Seu objetivo era criar um sentimento de identidade cultural brasileira.

Nesse tempo, havia uma polêmica em torno dos rumos para a língua portuguesa que dividida entre dois grupos compostos por intelectuais, escritores e linguistas, sendo um grupo mais conservador, que defendia a aprendizagem e o uso da língua portuguesa idêntica a de Portugal, enquanto outros defendiam que a língua a ser usada no Brasil deveria se aproximar daquela falada pelos brasileiros, pois traziam peculiaridades que a diferenciava da língua de Portugal. Sobre essa polêmica, nos explica Elia (2003, p. 139-140):

A questão da língua portuguesa no Brasil, também chamada questão da língua brasileira, surgiu no século XIX. Para isso concorreram dois fatores: a) a Independência, que, liberando o país da submissão oficial ao cânone português, permitiu que os brasileiros passassem a cuidar por si mesmos dos problemas relativos à língua herdada; b) o movimento romântico que buscava na alma do povo as bases da cultura nacional. Demais, como separar o que já era brasileiro do que permanecia português? Daí as "polêmicas da língua", em que, de um lado se pontificava um escritor brasileiro, de outro um português. 
Fazia parte deste segundo grupo seleto que via na fala popular um caminho para a nacionalização linguística em desapego a Portugal, o escritor romântico e político nacionalista José de Alencar (1829-1877). Suas obras foram escritas tendo como motivo de inspiração para seus temas, o brasileiro, na figura do índio dignificado como herói nacional nos romances indianistas, no sertanejo, homem forte e sábio e conhecedor do sertão em seus romances regionalistas, e nos costumes da elite carioca que se formava no novo império de D. Pedro II, nos romances urbanos e em suas peças para teatro.

Seus romances eram idealizados, típicos da corrente literária na qual se engajou, o Romantismo. A terra, a natureza e o povo brasileiro eram fortemente exaltados nas páginas dos folhetins em que foram lançados seus primeiros romances, no entanto, seu nacionalismo não se limitava às exuberantes paisagens brasileiras e ao heroísmo de seus índios: José de Alencar propunha uma mudança linguística na língua portuguesa falada no Brasil, algo que se aproximasse mais do linguajar popular e a inserção de um vocabulário com palavras da língua tupi. Essas propostas não ficaram na teoria, pois o próprio José de Alencar as utilizava em suas obras com o intuito de distinguir a língua portuguesa utilizada no Brasil da língua portuguesa de Portugal.

Este trabalho mostrará algumas dessas peculiaridades, evidenciando o caráter nacionalista de ruptura cultural com Portugal do escritor romântico, José de Alencar. Para realizarmos este estudo, seguiremos os três princípios sugeridos por Koerner (2014), os quais, segundo o autor, uma vez seguidos, orientam o historiador a evitar problemas metodológicos e epistemológicos enfrentados durante sua pesquisa. Koerner (2014, p. 56-57) comenta que dos vários problemas existentes, incluem:

Questões de periodização, contextualização e, geralmente, procedimentos de investigação, assim como questões relativas às mudanças de ênfase na prática linguística atual, a identificação de diferentes fases de desenvolvimento num quadro teórico particular, ou em períodos de tempo mais amplos, e no papel de fatores externos, por exemplo, os sócio-políticos, na aceitação ou rejeição de um referencial teórico.

Sendo assim, os princípios a seguir servem para evitar distorções das ideias sobre os linguistas, filósofos e gramáticos do passado: 1. contextualização histórica e intelectual (clima de opinião); 2. a análise do texto no seu próprio quadro teórico; e 3. uma descrição clara das ferramentas empregues na 
tentativa de tornar o texto mais facilmente acessível ao linguista moderno (KOERNER, 2014, p. 57-58).

Quanto ao primeiro princípio, Koerner (2014, p. 58) afirma que a contextualização histórica e intelectual é uma pesquisa sobre o clima de opinião, ou seja, as ideias filosóficas que circulavam na época, pois estas deixaram marcas nas ideias linguísticas; os fatores políticos e socioeconômicos também devem ser levados em conta, pois estes influenciam o pensamento e as opiniões de seu período e como se trata do estudo de uma língua, a educação linguística e o ensino da língua materna devem ser relacionados. Pesquisamos, então, o contexto sociopolítico em que José de Alencar atuou como escritor, para melhor entendermos o clima de opinião desta época e sua posição de nacionalista frente à emancipação cultural na qual buscavam os intelectuais de seu tempo.

José Martiniano de Alencar nasceu em Mecejana, Ceará, em 1829, vindo a falecer no Rio de Janeiro em 1877. Cresceu e estudou em São Paulo, onde se formou em Direito no ano de 1850. Dedicou-se ao jornalismo, à advocacia, à literatura e à política, tendo ocupado os cargos de Deputado e Ministro da Justiça. E, apesar de bem votado, não conseguiu realizar sua meta que era ser senador (CANDIDO \& CASTELO, 1992, p. 193).

José de Alencar nasceu em uma família engajada na política. Seu pai, José Martiniano Pereira de Alencar (1794-1860), foi padre e político no império, um liberal e revolucionário que, ao lado de sua mãe e avó do escritor, Bárbara Pereira de Alencar (1760-1832), participou da revolução republicana que teve origem em Pernambuco. Tal revolução foi severamente reprimida pelas tropas fiéis a D. João VI (1767-1826) e ambos, o pai e a avó de Alencar, foram presos nesta ocasião, passando quatro anos em uma prisão na Bahia (MAGALHÃES JUNIOR, 1970, p. 3).

A história dessas marcas começou na infância, atirado nas lides políticas, meu pai quase não esteve presente em casa nos primeiros anos de vida e, quando chegava, era preciso mostrar-Ihe os progressos dos filhos. Só quando nos transferimos para o Rio de Janeiro pude conviver com ele, ou, melhor, usufruir de sua presença ao longe. Quem cuidava de mim era a minha avó e minha mãe. A lembrança de minha avó, d. Bárbara Pereira de Alencar, é marcante pelas histórias que a heroína da Revolução de 1817 contava (ALENCAR apud RODRIGUES, 2001, p. 17).

Quando criança, sua casa, na rua conde, 55, onde residia com sua família, era palco de reuniões em que eram recebidos membros do Clube Maiorista, 
cujo presidente, o conselheiro Antônio Carlos Ribeiro de Andrada Machado e Silva (1773-1845), e o secretário, o então senador Alencar, seu pai. A pauta de muitas dessas reuniões era a grande revolução parlamentar da maioridade de D. Pedro II. José de Alencar era apenas uma criança e, como tal, ainda não entendia o motivo daquelas reuniões feitas sempre às escondidas (ALENCAR, 1990, p. 24-25).

Assim, José de Alencar nasceu e cresceu em uma época de revoltas contra a coroa portuguesa. $\mathrm{Na}$ sua infância, presenciou o movimento de maioridade de D. Pedro II e a participação do parlamento na administração do Brasil imperial que aos poucos chegaria ao fim. O ocidente se voltava contra o absolutismo monárquico, como foi o caso da França e dos Estados Unidos.

Em São Paulo, quando cursava o preparatório para a faculdade de Direito, o jovem José de Alencar morava com outros estudantes, e um deles costuma emprestar livros da literatura francesa de seu amigo Octaviano, o qual era colecionador do estilo. Foi aí que se tornou um leitor e admirador dos romances franceses, segundo suas próprias palavras em sua autobiografia:

Meu companheiro de casa era dos amigos de Otaviano, e estava no direito de usufruir sua opulência literária. Foi assim que um dia vi pela primeira vez o volume das obras completas de Balzac (...). Gastei oito dias com o Grenadière; porém em um mês depois acabei o volume de Balzac; e no resto do ano li o que então havia de Alexandre Dumas e Alfredo Vigny, além de muito de Chateaubriand e Vitor Hugo. A escola francesa, que eu então estudava nesses mestres da moderna literatura, achava-me preparado para ela. 0 molde do romance, qual mo havia revelado por mera casualidade aquele arrojo de criança a tecer uma novela com fios de uma ventura real, fui encontrá-lo fundido com a elegância e beleza que jamais the poderia dar (ALENCAR, 1990, p. 40-41).

Os romances franceses trouxeram um novo olhar para o escritor, que se sentia apaixonado por esta nova literatura que viera a conhecer quando era estudante. Os escritores que ele citou no trecho acima fizeram parte do Romantismo francês, os quais assumiram uma postura antimonárquica, antiabsolutista e contrária ao racionalismo exercido no classicismo, voltando-se, então, para a história de sua pátria.

Os escritores românticos foram estimulados pelas ideias do filósofo francês Jean-Jacques Rousseau (1712-1778), como explica Coutinho e Coutinho (2004, p. 6, grifos do autor): "Rousseau é um grande europeu, cuja presença no século serve de ponto de irradiação e de convergência das principais ten- 
dências que definirão a fisionomia romântica, a ponto de ser, por alguns, cognominado o pai do Romantismo".

Rousseau recebeu tal alcunha, pois algumas de suas ideias foram consideradas precursoras do movimento, tais como o sentimento de apego à natureza com características subjetivistas, próprias do Romantismo. Em sua obra Discurso Sobre a Origem e o Fundamento da Desigualdade entre os Homens, publicada em 1755, Rousseau traz à tona uma reflexão sobre as desigualdades sociais menciona que o homem nasce puro e bom, mas a sociedade e seus valores o corrompem.

Dessa forma, o filósofo sugere ao homem uma busca em seu interior pelo homem natural, selvagem, puro, honesto, sem as marcas corrompidas pela sociedade em que vive. Daí o surgimento de características marcantes do Romantismo, como a fuga da realidade ao subjetivismo, o apelo emocional e sentimental das obras e o "mito do bom selvagem" encontrado em Peri, Iracema e Ubirajara, personagens criados por José de Alencar.

O escritor teve contato com Rousseau ainda na faculdade, conforme ele próprio atesta (ALENCAR apud RODRIGUES, 2001, p. 24): “foi nesse momento que tomei contato com filósofos da política, como Rousseau e Montesquieu, que me ajudaram a refletir sobre a organização política brasileira”.

Quanto à educação e ao ensino da Língua Portuguesa, em seu tempo, se restringia à elite do país, sendo que a maior parte da população era analfabeta. Vale lembrar que quando José de Alencar iniciou seus estudos, há menos de um século ocorria no Brasil a Reforma Pombalina, que em nome da coroa portuguesa proibiu o ensino da Língua Geral, instaurando a obrigatoriedade da Língua Portuguesa nas escolas, língua de prestígio e com a qual o Brasil fazia seus negócios com o mundo.

Com isso podemos considerar que a maioria dos brasileiros nessa época, principalmente no interior do país, ainda falava uma língua bem próxima da língua geral, um misto de português e do tupi, que durante muito tempo foi ensinada aos colonizadores, estrangeiros e escravos para facilitar a comunicação. A Língua Portuguesa ensinada nas poucas escolas que havia no país ainda era um privilégio da minoria. $\mathrm{O}$ que podemos observar no fragmento abaixo, conforme atesta Silva Neto (s.d., p. 61-78):

No primeiro século, quando se tentou incorporar o índio à sociedade portuguesa e quando ele se tornava indispensável para a devassa da terra - foi grande a influência da língua geral. Era, então, natural que os conquistadores recém- 
-chegados procurassem conhecê-la. (...) 0 português era a língua da administração: só em português era possível entender-se oficialmente com os agentes do Estado. Рara aspirar aos cargos públicos (aliás, sempre tão apetecidos) егa preciso o conhecimento do português.

Assim, entendemos que José de Alencar, cheio do espírito revolucionário encontrado na literatura francesa e que de certa forma coincidia com a educação herdada de sua família e o período político e cultural em que se encontrava o país, surge com a ideia de renovar a literatura no Brasil, acrescentando à língua portuguesa escrita e ensinada nas escolas por meio de gramáticas, vocábulos próprios do falar do brasileiro.

Sua ideia não foi bem vista pela elite, pois os documentos entre Brasil e Portugal sempre foram escritos em língua portuguesa, desde os tempos da colônia, e isso poderia trazer problemas para o Brasil que vivia de exportar produtos para Portugal e outros países. José de Alencar foi duramente criticado por sua maneira de pensar e escrever. As críticas que recebia dos conservadores e gramáticos atravessaram o Atlântico, sendo que até escritores e intelectuais portugueses deixaram seus pesados julgamentos aos trabalhos do escritor.

A fim de mostrar as inovações linguísticas feitas por José de Alencar, utilizaremos o princípio da imanência, que diz respeito a uma análise do texto no seu próprio quadro teórico, ou seja, “o quadro geral da teoria a ser investigada, assim como a terminologia usada no texto, devem ser definidos internamente e não em referência à doutrina linguística moderna" (KOERNER, 2014, p. 59). Sendo assim, selecionamos para esta análise, trechos de romances de José de Alencar em que o escritor propõem uma ruptura cultural com Portugal, por meio da distinção entre as línguas usadas em ambos os países. Essas inovações estão no campo lexical e sintático, porém para este trabalho, enfocaremos o campo lexical.

Com relação ao léxico, o uso de neologismos, costume próprio dos poetas, colhemos deste escritor um trecho da obra Iracema, em sua primeira edição, de 1865, em que há um verbo criado pelo escritor para representar o ruído produzido pela passagem do vento entre as folhas das árvores (ALENCAR, 1865, p. 20): “Uma historia que me contarão nas lindas várzeas onde nasci, à calada da noite, quando a lua passeava no ceo argenteando os campos, e a brisa rugitava nos palmares". Observemos que, em notas do autor ao final da narrativa, o autor se justifica tomando como exemplo o poeta português, Felinto Elisio (1734-1819), que também criou o seu verbo (ALENCAR, 1865, 
p. 163-164): “(...) ll.Rugitar - é um verbo de minha composição para o qual peço venia. Felinto Elisio creou ruidar de ruído”.

O romance Iracema (1865) também se destaca pela linguagem poética. Foi considerado pelos críticos ao longo dos anos como um verdadeiro poema em prosa, estilo que ainda não havia sido usado por outro escritor em língua portuguesa, o que fez com que o estilo de Alencar fosse original. Essa originalidade é resultado dos esforços em recriar uma literatura de língua portuguesa que fosse realmente brasileira.

Logo depois da Independência (1822), surgiu no Brasil a questão de saber em que língua deveria expressar-se a literatura brasileira, e muitos intelectuais optaram por denominações como "língua nacional" ou mesmo "língua brasileira" - denominações nas quais Portugal não estava presente. Alguns escritores foram além de uma atitude meramente programática, usando uma linguagem literária em que os "brasileirismos" tinham um papel considerável. José de Alencar foi um desses escritores, e o melhor exemplo desse estilo é a obra Iracema (1865), que, embora se apresentasse como romance, tem todas as características de um longo poema em prosa. Diferentemente de tudo quanto tinha aparecido até então em língua portuguesa, o estilo dessa obra não deixou de provocar reações iradas do outro lado do Atlântico: o filólogo português Pinheiro Chagas fez dele uma avaliação muito depreciativa, à qual Alencar responderia acrescentando à segunda edição de Iracema (1870) um post-scriptum que ficou célebre (ILARI; BASSO apud PRESTES, 2010, p. 147).

Podemos confirmar a ira dos puristas da língua, lendo a opinião do filólogo português Pinheiro Chagas (1842-1895) em sua crítica ao romance Iracema (1865), cujo autor denominou como "lenda do Ceará":

0 defeito que eu vejo nessa lenda, o defeito que vejo em todos os livros brasileiros, e contra o qual não cessarei de bradar intrepidamente é a falta de correção na linguagem portuguesa, ou antes a mania de tornar o brasileiro uma língua diferente do velho português, por meio de neologismos arrojados e injustificáveis e de insubordinações gramaticais, que (tenham cautela!) chegarão a ser risiveis se quiserem tomar as proporções duma insurreição em regra contra a tirania de Lobato (CHAGAS apud ELIA, 2003, p. 140).

José de Alencar, ao levar para a literatura os vocábulos indígenas e a fala cotidiana do brasileiro, enriqueceu o idioma português, reflexo do natural desenvolvimento da nação e os contatos linguísticos das varias etnias aqui 
presentes resultado da miscigenação, desde o período colonial, como mostra Barbosa (1958, p. 79):

O fato é que, no período colonial, com uma unidade ainda não muita definida, e comunicações precárias, todas as forças concorriam para a diferenciação da linguagem, sobretudo quando elementos índios, e a escravatura negra proporcionavam outras contribuições para a linguagem corrente.

Esses “elementos índios” dos quais Barbosa se refere são os vocábulos encontrados durante a leitura dos romances indianistas de José de Alencar, como neste fragmento de Iracema, publicado em 1865:

Além, muito além dáquella serra, que ainda azula no horisonte, nasceu Iracema: Iracema, a virgem dos lábios de mel, que tinha os cabellos mais negros que a aza da graúna, e mais longos que seo talhe de palmeira. 0 favo da jaty não егa doce como seo sorriso; nem a baunilha rescendia no bosque como seo hálito perfumado (ALENCAR, 1865, p. 4).

A começar pelo nome da personagem protagonista da obra, Iracema, percebemos que o autor utiliza um aposto explicativo, como se estivesse apenas exaltando as qualidades da índia, mas Alencar está, na verdade, traduzindo o nome da personagem, que ele próprio explica nas notas do autor, ao final do romance: "I. Iracema. Em guarany significa lábios de mel - de ira - mel e tembe labios, Tembe na composição altera-se em ceme, como na palavra ceme-yba" (ALENCAR, 1865, p. 164); virgem porque segundo a lenda tabajara, a filha do pajé deveria se manter intocada sexualmente para guardar o segredo da jurema e, assim, preparar a bebida de tupã ao pajé.

O mesmo acontece em Ubirajara, livro lançado em 1874, que conta a história do jovem Jaguaré, caçador da tribo Araguaia que, ao vencer o guerreiro da tribo inimiga, passa a ser chamado de Ubirajara. Observemos nestes dois fragmentos a seguir que José de Alencar trabalha com o nome da personagem e seu significado em tupi, dando sentido ao enredo do texto. No fragmento número 1 , um trecho da obra e, em seguida, o de número 2 , a explicação do próprio Alencar em notas do autor:

1: Pela margem do grande rio caminha Jaguaré, o joven caçador. 0 arco pende-lhe ao hombro, esquecido e inútil. As flechas dormem no coldre da uiraçaba. Os veados saltam das moitas de ubaia e vem retouçar na gramma, zombando 
do caçador. Jaguaré não vê o timido campeiro, seus olhos buscam um inimigo capaz de resistir-lhe ao braço robusto. 0 rugido do jaguar abala a floresta; mas o caçador também despreza o jaguar, que já cançou de vencer. Elle chama-se Jaguaré, o mais feroz jaguar da floresta; os outros fogem espavoridos quando de longe o pressentem (ALENCAR, 1874, p. 7).

2: Jaguaré. Nome composto de Jaguar, a onça e o suffixo é que na lingua lupy reforça empaticamente a palavra a que se liga. Jaguaré, significa pois, a onça, verdadeiramente onça, digna do nome, por sua força, coragem e ferocidade (ALENCAR, 1874, p. 164).

A presença do "tupinismo" em sua obra não é marca apenas dos romances indianistas como vimos nos fragmentos citados. Em O Sertanejo, publicado em 1875, o escritor também utiliza desta característica, como no seguinte trecho: "Anhamun recebeu sua flecha que tu lhe mandaste, chefe dos tapijaras; e soprou o boré para convocar os seus guerreiros. Elle veio pelo rasto dos inimigos" (ALENCAR, 1875, p. 296). Ao final do livro, em notas do autor, ele explica o significado da palavra utilizada: “Tapyjara. É uma palavra tupy de origem moderna, e significa vaqueiro. Os índios chamavam ao boi, anta grande" (ALENCAR, 1875, p. 341). As demais palavras de origem tupi presentes nos trechos escolhidos para esta análise, assim como as inúmeras palavras que fazem parte de seus romances vêm com explicações em notas do autor.

Para finalizar, observaremos o terceiro princípio, o qual Koerner (2014) denomina "princípio da adequação", deve ser feita uma descrição das ferramentas empregues na tentativa de tornar o texto mais facilmente acessível ao linguista moderno, como explica:

Só depois de terem sido concisamente seguidos os dois primeiros princípios, de forma a que uma dada manifestação linguística tenha sido compreendida no seu contexto histórico original, o historiógrafo pode aventurar-se a introduzir aproximações modernas do vocabulário técnico e do quadro conceptual apresentado na obra em questão. Talvez possamos chamar a este último passo de 'princípio da adequação' (KOERNER, 2014, p. 59).

As análises que foram realizadas no tópico anterior nos faz refletir sobre a importância que o escritor deu aos vocábulos de origem indígena, como meio de diferenciar a língua portuguesa utilizada no Brasil em relação à língua de Portugal. Pode-se dizer que a inserção dessas palavras representou para o Brasil uma independência linguística, uma vez que, antes de José de Alencar, durante o período colonial, eram ensinadas apenas como fonte de conhecimento para a 
colonização, sendo que os portugueses as aprendiam para se comunicar com os índios a fim de que eles os levassem ao encontro das riquezas minerais.

O que havia antes do século XIX eram apenas métodos e dicionários bilíngues que tratavam de estudos dessas palavras como língua brasílica, tais como o Diccionario portuguez, e brasiliano (1795), "obra necessaria aos ministros do altar, que emprehenderem a conversão de tandos milhares de Almas que ainda se achão dispersas pelos vastos certões do Brasil, sem o lume da Fé, e Baptismo.” (BIBLIOTECA BRASILIANA MINDIM, s/d), escrito por José Mariano da Conceição Veloso (1742-1811), publicado em Lisboa no ano de 1795, ou anterior a isto, a clássica gramática escrita pelo Padre José de Anchieta (1534-1597), Arte de grammatica da lingoa mais usada na costa do Brasil, publicada em Coimbra em 1595.

Conforme mencionado anteriormente, foi a partir do século XIX, após a independência do Brasil, que começaram a surgir dicionários e gramáticas com nomes nacionais em que se sugeria uma língua portuguesa renovada, ou seja, uma língua nacional. São exemplos destes, o Vocabulario brasileiro para servir de complemento aos diccionarios da lingua portugueza de Braz da Costa Rubim (18171870), publicado no Rio de Janeiro, em 1856, e o Diccionario da lingua brasileira, de Luiz Maria da Silva Pinto (1780-1869), publicado em Ouro Preto, em 1832.

\section{CONSIDERAÇÕES FINAIS}

A independência do Brasil trouxe um sentimento de nacionalismo aos intelectuais, escritores, linguistas e filólogos brasileiros, que se viam animados com os acontecimentos da época. Existiram aqueles defendiam projetos de construção de uma língua nacional, que se afastasse da língua culta portuguesa se aproximando mais do falar brasileiro. Surgiram livros e dicionários que tentaram traduzir este anseio de ruptura linguístico-cultural.

José de Alencar (1829-1877), escritor e político nacionalista, viu nos vocábulos de origem tupi um motivo para a nacionalização da língua portuguesa usada no Brasil, pois tais vocábulos presentes na flora e fauna brasileiras e, por isso, utilizados pelo povo no seu dia-a-dia, uma vez inseridos na língua trazida pelos colonizadores, seria, o caminho para sua nacionalização.

Por meio dos três princípios sugeridos por Koerner (2014) para a realização de um trabalho de historiografia, vimos que, antes do século XIX, o vocabulário dos aborígenes era estudado apenas para conhecimento do coloniza- 
dor e que durante este século deu-se início sua inserção em dicionários de língua portuguesa escritos no Brasil. Os trechos das obras de José de Alencar utilizados para a realização deste trabalho fazem parte desta época, em que havia uma questão em torno da nacionalização da língua. Foram estudadas a primeira edição de Iracema (1865), Ubirajara (1874) e O Sertanejo (1875), conforme o segundo princípio koerneano.

\section{José de Alencar and brazilianness: a historiographic reading}

\section{Abstract}

We present a reading about José de Alencar trying to show the writer's intention to renew the Portuguese language used in Brazil, a product of his nationalistic aspirations, a reflection of a society that lived in a country of recent independence and that sought for its cultural emancipation. For this, the author seeks in the language of the Indians new words for Brazilian Portuguese. The choice of theme is justified by the importance of reflecting and discussing the cultural achievements of this historical moment, of formation and characterization of the national culture. Thus, the general objective of this work is to show that José de Alencar was a writer engaged with the political and cultural issues of his time, with the specific objective of analyzing excerpts from some of his works highlighting "Tupinism" as the peculiarities that differ from European Portuguese. The methodology used to carry out this work is of a bibliographical nature backed by the historiographical bias based on the work of Koerner (2014) that presents us three principles for a work of linguistic historiography. The aspects of the author's biography relevant to the work, as well as the events of the time in which he acted, will be seen in Candido and Castelo (1992), Coutinho and Coutinho (2004), Magalhães Júnior (1970) and Rodrigues (2001).

\section{Keywords}

José de Alencar. Portuguese language. Cultural breakdown.

\section{REFERÊNCIAS}

ALENCAR, J. de. Como e porque sou romancista. Adaptação ortográfica Carlos de Aquino Pereira. Campinas: Pontes, 1990.

41 
ALENCAR, J. de. Iracema: lenda do Ceará. Rio de Janeiro: Typ. de Viana \& Filhos, 1865. Disponível em: <http://www.brasiliana.usp.br/handle/1918/00178300>. Data de acesso: 12 dez. 2016.

ALENCAR, J. de. O Sertanejo. Rio de Janeiro: B. L. Garnier, 1875. Disponível em: <http://www.brasiliana.usp.br/handle/1918/00181520>. Data de Acesso: 20 out. 2016.

ALENCAR, J. de. Ubirajara. Rio de Janeiro: B. L. Garnier, 1874. Disponível em: <http: //www. Brasiliana.usp.br/handle/1918/00016000>. Data de Acesso: 20 out. 2016.

BARBOSA, L. S. A Língua Portuguesa e a Unidade do Brasil. Rio de Janeiro: José Olympio, 1958.

BIBLIOTECA BRASILIANA MINDIM. Disponível em: <www.brasiliana.usp.br>. Acesso em: 20 out. 2016.

CANDIDO, A.; CASTELO, J. A. Presença da literatura brasileira: História e Antologia - das Origens ao Realismo. 5. ed. São Paulo: Bertrand Brasil, 1992.

COUTINHO, A. dos S.; COUTINHO, E. de F. A literatura no Brasil - Era romântica. Parte II. 7. ed. rev. e atual. São Paulo: Global, 2004. 3 v.

ELIA, S. Fundamentos histórico-linguísticos do português do Brasil. Rio de Janeiro: Lucena, 2003.

KOERNER, E. F. K. Quatro décadas de historiografia linguística: estudos selecionados. Coleção Linguística 11. Braga, Portugal: Publito, Estúdio de Artes gráficas - Centro de Estudos em Letras da Universidade de Trás-os-Montes e Alto Douro, 2014.

MAGALHÃES JUNIOR, R. José de Alencar e sua época. Rio de Janeiro: Lisa Livros Irradiantes, 1970.

PRESTES, M. L. de M. Para além da literatura, a língua: José de Alencar e a identidade do português brasileiro. Ciências \& Letras, n. 47, p. 137-152. 2010. Disponível em: <http://seer3.fapa.com.br/index.php/arquivos/article/viewFile/44/38>. Data de Acesso: 15 dez. 2016.

RODRIGUES, A. E. M. O poeta armado do século XIX. Rio de Janeiro: FGV, 2001.

SILVA NETO, S. Capítulos de História da Língua Portuguesa no Brasil. Rio de Janeiro: Livros de Portugal, s.d. 